\title{
Long term outcome of ventilated asthmatics
}

\author{
P C Seddon, D P Heaf
}

\begin{abstract}
Over a 25 year period, 31 asthmatic children received artificial ventilation for acute asthma at Alder Hey Children's Hospital on 48 occasions. Altogether 47 episodes occurred from 1971-89, with no decline in the number of episodes per year (mean 2.5) over this period. Eight children died during intermittent positive pressure ventilation (IPPV), and of the 23 survivors, three further children had subsequently died from asthma. Seventeen children were followed up for more than a year after IPPV. Sixteen still had symptoms of asthma and over half had symptoms every day. Ten cooperated with pulmonary function tests: mean forced expiratory volume in one second was $83 \%$ of predicted and geometric mean provocative histamine concentration $\left(\mathbf{P C}_{20}\right)$ was $2.1 \mathrm{mg} / \mathrm{ml}$. Since the follow up study a fourth patient had died from asthma. IPPV continues to be required for a small number of asthmatic children each year. The survivors remain a high risk group with significant continuing morbidity and mortality.
\end{abstract}

Intermittent positive pressure ventilation (IPPV) using mechanical ventilators was developed during the 1950s and started to be used regularly to treat acute respiratory failure during the 1960s. The first paper to describe its use in asthmatic children reported a generally good outcome, ${ }^{1}$ and subsequent series, all from North America, have tended to show low mortality and complication rates. ${ }^{2-4}$ No sizable European series of IPPV in childhood asthma has been reported, the largest comprising six episodes. ${ }^{5}$ There has been no previous attempt to assess the subsequent outcome of children who survive IPPV for asthma. We report the experience of ventilating asthmatic children in a regional paediatric intensive care unit in a large children's hospital over a 25 year period. We describe the prior characteristics of children who required IPPV, the clinical course, and outcome of the episodes. Finally we document the subsequent outcome of children who survived the IPPV episodes.

Respiratory Unit, Alder Hey

Children's Hospital,

Liverpool

P C Seddon

D P Heaf

Correspondence to:

Dr P C Seddon,

Department of

Neonatal Medicine

Southmead General Hospital, Westbury-on-Trym,

Bristol BS10 5NB.

Accepted 10 August 1990

Cases were found from the register of the Regional Paediatric Intensive Care Unit of Alder Hey Children's Hospital, which has been kept since the unit opened in 1964. Case notes were consulted of all admissions to the unit for whom asthma was recorded as one of the diagnoses. Only children who were ventilated for respiratory failure due to asthma were included in the study. This yielded 31 asthmatic children ventilated on 48 occasions between November 1964 and March 1989.

The first part of the study was a retrospective survey of the characteristics of asthmatic children who required IPPV, the clinical course of the illness which led to respiratory failure, and the course and outcome of the IPPV episodes themselves. Details were extracted from the case notes by one investigator (PCS) using a proforma. If the child's regular care was in another hospital, the local hospital notes were reviewed also.

The second part was a follow up study of the children who had survived their episodes of IPPV for respiratory failure, excluding two children who were ventilated within 12 months of the study. The median duration of follow up (range) was 11 years $(1 \cdot 1-15 \cdot 6)$ and median age at follow up (range) was 15 years $(2 \cdot 6-26 \cdot 0)$. We first wrote to the general practitioner with a request for permission to contact the family, and a questionnaire seeking details of the patient's current symptoms and treatment. We then wrote to the patient or parents (depending on age) inviting them to attend for assessment. Those who agreed were assessed by three methods.

- A questionnaire administered personally to the patient/parents asking about their current symptoms, treatment, and strategies for dealing with a sudden severe attack.

- Spirometry, using a pneumotachograph system (Vitalograph Compact) to measure peak expiratory flow (PEF), forced expiratory volume in one second $\left(\mathrm{FEV}_{1}\right)$, and forced vital capacity (FVC). The figures used for analysis were taken from the loop with the highest sum of FEV 1 and FVC, and were expressed as percent predicted for height. ${ }^{6}$

- Histamine challenge, using the tidal breathing technique of Cockcroft et al. ${ }^{7}$

All asthma medications were discontinued 12 hours before assessment, except in one patient who was unable to manage without salbutamol every four hours. Three patients under 5 years old at follow up were assessed by (parental) questionnaire only. Two patients declined to attend for assessment but completed the questionnaire by post. Two patients failed to respond to three postal invitations: for these only the general practitioner assessment is available.

\section{Results}

SECULAR TRENDS

One child was ventilated in 1964 and there were 
Table 1 IPPV episodes and admissions at Alder Hey for asthma, and asthma deaths in Mersey region, in two yearly periods, 1972-87

\begin{tabular}{|c|c|c|c|c|c|c|c|c|}
\hline & $72 / 73$ & $74 / 75$ & $76 / 77$ & $78 / 79$ & $80 / 81$ & $82 / 83$ & $84 / 85$ & $86 / 87$ \\
\hline \multirow{3}{*}{$\begin{array}{l}\text { IPPV } \\
\text { (Alder Hey) } \\
\text { Admissions } \\
\text { (Alder Hey) } \\
\text { Deaths 0-14 years } \\
\text { (Mersey region) }\end{array}$} & 3 & 7 & 8 & 5 & 5 & 7 & 2 & 4 \\
\hline & 292 & 410 & 582 & 716 & 1134 & 1570 & 1618 & 1679 \\
\hline & NA & 2 & 5 & 4 & 3 & 4 & 3 & 3 \\
\hline
\end{tabular}

NA, figures not available.

no further episodes until 1971. Table 1 shows the number of IPPV episodes for asthma from 1972 to 1987 inclusive. There is no clear trend up or down. The total number of asthma admissions to Alder Hey over the same period has increased appreciably, as reported elsewhere, ${ }^{8}$ and the number of childhood asthma deaths in Mersey region has remained static. The proportion of IPPV episodes after transfer from other hospitals increased from $20 \%$ between 1970 and 1979 , to $64 \%$ between 1980 and 1989 . The threshold for instituting IPPV has probably not altered as the arterial $\mathrm{pH}$ before intubation had not changed significantly between the first 10 episodes (mean $7 \cdot 10)$ and the last 10 episodes $(7 \cdot 11)$.

\section{PATIENT CHARACTERISTICS}

The age distribution (figure) was bimodal, with the main peak at 2 years of age, very few cases in the middle childhood years, and a smaller peak in the teens. This distribution is similar to that for childhood asthma deaths in Britain, ${ }^{9}$ but with the size of the peaks reversed. The male:female ratio was $1 \cdot 2: 1$. The median age of asthma onset was 1 year (range 5 months to 5 years).

Most of the children had a history of frequent admissions due to asthma. Twenty of 31 had been admitted more than twice in the preceding year, eight had only occasional admissions, and three children required IPPV on their first admission. Despite this, before their first IPPV episode more than half (17/31) were receiving bronchodilators alone or no treatment for their asthma. Seven were on sodium cromoglycate, four on inhaled steroids, and three on systemic steroids or adrenocorticotrophic hormone.

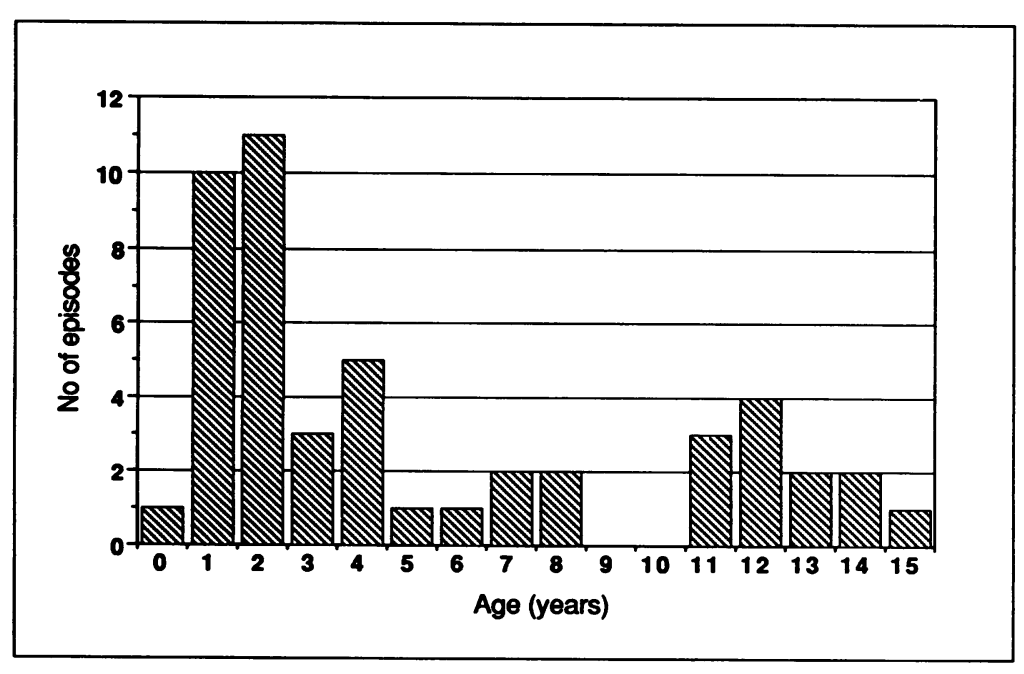

Number of IPPV episodes occurring at each age.
COURSE OF ATTACK BEFORE INTUBATION

The median recorded duration of the attack of asthma before admission was 10 hours (range $0-120)$; 33/48 were 24 hours or less. In most cases there was no clear precipitating event for the attack; one child required IPPV after an allergen challenge, and one developed bronchospasm during a general anaesthetic.

The median interval between admission and ventilation was seven hours; $38 / 48$ episodes progressed to respiratory failure despite at least four hours of hospital treatment. Treatment received between admission and intubation included intravenous hydrocortisone in 40/48 episodes, intravenous aminophylline in 34 , intravenous salbutamol in eight, nebulised salbutamol in 15 , subcutaneous adrenaline in eight, and sedatives in eight. Changes in treatment evident over the years were the disappearance of subcutaneous adrenaline (last used in 1977) and of sedatives (1979), and the appearance of intravenous (1975) and nebulised (1979) salbutamol. Surprisingly, since 1979 intravenous salbutamol had been used during only one episode, although high dose infusions have been shown capable of reversing respiratory failure in asthma. ${ }^{510}$

The decision to intubate was taken on a combination of clinical evidence and blood gases in 30 cases. For these episodes, the mean pH (SD) before intubation was 7.09 $(0 \cdot 1)$ and mean carbon dioxide tension (SD) was $11.6(4.5) \mathrm{kPa}$. The rest had no blood gases recorded before intubation. One child was already intubated for a general anaesthetic and three were intubated on arrival at hospital after a respiratory arrest in home $(n=2)$ or ambulance $(n=1)$. In the remaining 14 episodes the child progressed to respiratory failure in hospital, over a median time of six hours, without having blood gases recorded. By the time they were intubated, many children had developed evidence of cerebral or cardiac hypoxia. Two had a respiratory arrest in hospital and one a cardiac arrest during intubation. Six were semiconscious, five unconscious, and two having fits before intubation.

COURSE AND OUTCOME OF IPPV

Median duration (range) of IPPV was three days (1-27). Volume cycled ventilators were used and all children received a muscle relaxant (turbocurarine chloride in $45 / 48$ episodes) as well as sedation.

The commonest complications occurring during the $\mathbf{4 8}$ episodes were as follows. Lobar collapse occurred in 29 episodes (60\%), and usually involved one or both upper lobes (28 episodes). Pneumomediastinum (leading to subcutaneous emphysema) was seen in $13(27 \%)$ and 
pneumothorax in $10(21 \%)$. Hypoxic-ischaemic encephalopathy developed during nine episodes, three of which had been preceded by cardiorespiratory arrest and one by hypoxic fits. None of the survivors suffered long term neurological sequelae. Transient proximal myopathy, which occurred in six episodes, has been reported previously after IPPV for asthma and is presumed to be due to steroids. ${ }^{11}$ Inappropriate antidiuretic hormone secretion (defined as hyponatraemia and fluid retention) occurred in six episodes, five of which were associated with hypoxic-ischaemic encephalopathy.

Eight of the 48 episodes (17\%) had a fatal outcome. Cardiorespiratory arrest before IPPV, and hypoxic-ischaemic encephalopathy both predicted a poor prognosis. Five of six episodes preceded by a cardiorespiratory arrest were fatal, even though in three of the five fatal episodes the arrest occurred on the intensive care unit. Six of nine episodes complicated by hypoxic-ischaemic encephalopathy were fatal, and in five of these six there was evidence of cerebral hypoxia before intubation. Blood gases before intubation, where available, did not predict outcome, but those children intubated after an arrest had not usually had blood gases recorded. None of the other complications was statistically associated with a fatal outcome.

Multiple IPPV episodes were associated with a poor outcome: of the seven children ventilated more than once, five eventually died during an episode $(p<0.05)$. Age also appeared to be a factor: the mean age at ventilation for fatal episodes (9.6 years) was significantly older than for non-fatal episodes (5 years) $(\mathrm{p}<0.005)$. Children who had already received steroid treatment at home before their first IPPV episode were significantly more likely to die $(\mathrm{p}<0.05)$.

\section{LONG TERM OUTCOME}

Eight of the 31 children had died during IPPV. Of the 23 survivors, three were found to have died subsequently, and one patient could not be traced. Of the 19 definite survivors, two had been ventilated less than 12 months before the follow up study. Only data from the 17 patients with at least 12 months' follow up will be presented.

Information from the general practitioner questionnaire was available for all 17 patients. One was said to be asymptomatic, nine (53\%) had chronic daily symptoms, and seven had intermittent symptoms. Most patients were being prescribed prophylaxis: sodium cromoglycate in three cases and inhaled steroids in 10 (with additional theophylline in five). Three were only prescribed bronchodilators, but all three had chronic daily symptoms and clearly merited prophylaxis.

The personal questionnaire was completed for 15 patients. Nine of $15(60 \%)$ experienced wheezing every day and two of these were constantly wheezy. Six (40\%) awoke wheezing more than once a week and three were disturbed every night. Fourteen (93\%) had more than 10 acute attacks per year, and five (33\%) had missed two weeks of work or school due to asthma in the previous three months. Thirteen $(87 \%)$ wheezed regularly on exercise.

All these patients had, by definition, suffered at least one life threatening asthma attack, and of the nine sets of parents interviewed, four had been afraid that their child would die during at least one other attack. Despite this, surprisingly few families had a clear plan of action, or additional treatment available, in the event of a rapidly developing severe attack. Five had a nebuliser at home, one having home oxygen also. One knew how to take high dose $\beta$ agonist by valved spacer. The remaining nine had no contingency for dealing with a more severe attack while awaiting further help. None of the 15 had reserve oral steroids at home. Although 12 were 5 years old or more, only one had a peak flow meter at home. In the event of a severe attack, eight would contact their general practitioner initially and seven would go directly to the local hospital. Only six had an 'open access' arrangement with the hospital. Thirteen had a family car and 11 said they would use it in preference to calling an ambulance.

Ten patients attended for pulmonary function testing: their mean (SD) value as percent predicted for $\mathrm{FEV}_{1}$ was 82.9 (12.9), for peak flow $98 \cdot 8(14 \cdot 7)$, and for forced respiratory ratio $78 \cdot 7$ (9.5). Five had FEV 1 values less than $80 \%$ of predicted. Geometric mean provocative histamine concentration $\left(\mathrm{PC}_{20}\right)$ was $2 \cdot 1$, range $0 \cdot 23$ to $32 \mathrm{mg} / \mathrm{ml}$.

\section{LATE DEATHS}

The three children who died between the IPPV episode and follow up had all suffered from severe asthma since early childhood and were on long term systemic steroids. Since completing the study we have learnt of one more death (case 4). In all four cases the fatal incident was clinically a rapidly progressing asthma attack, though only one child (case 2 ) had a postmortem examination. This showed typical changes of acute on chronic severe asthma. The details of these four children are summarised in table 2 .

In all, nine of the 28 children who survived

Table 2 Details of children who survived IPPV but died subsequently

\begin{tabular}{lclclll}
\hline Case No & $\begin{array}{l}\text { Age at } \\
\text { asthma onset }\end{array}$ & $\begin{array}{l}\text { Age at } \\
I P P V\end{array}$ (years) & $\begin{array}{l}\text { Age at } \\
\text { death (years) }\end{array}$ & Regular treatment & Manner of death \\
\hline 1 & 6 months & 12 & 14 & $\begin{array}{c}\text { Prednisolone, isoprenaline, ephedrine } \\
\text { Prednisolone, beclomethasone, } \\
\text { sodium cromoglycate, } \\
\text { theophylline, salbutamol } \\
\text { Prednisolone, beclomethasone, } \\
\text { aminophylline, salbutamol } \\
\text { Budesonide, theophylline, } \\
\text { salbutamol }\end{array}$ & $\begin{array}{l}\text { Acute asthma at home } \\
\text { Acute asthma at home }\end{array}$ \\
3 & 2 & 3 & 3 & $\begin{array}{c}\text { Acute asthma in hospital } \\
\text { Respiratory arrest at home; } \\
\text { IPPV discontinued after one } \\
\text { week (brain dead) }\end{array}$ \\
\hline
\end{tabular}


their first IPPV episode have subsequently died from their asthma, at median (range) 1.6 years $(0.5-8 \cdot 4)$ from their first IPPV.

\section{Discussion}

The treatment of asthma has changed considerably since 1964, and this was apparent among our ventilated patients. With more effective treatment available, one might expect the numbers of asthmatic children requiring ventilation to decline, but in our regional intensive care unit this is not occurring. This is probably because over the same period, admissions for acute asthma have increased considerably, so that in fact the proportion of admissions requiring ventilation has declined. An increase in tertiary referrals may also have contributed.

Asthmatic children who require IPPV tend to be either the very young or teenagers, to have developed asthma at an early age and required multiple admissions, have an equal sex distribution (in contrast to the overall male predominance in childhood asthma), and have been previously undertreated. In all these characteristics they resemble children who die from acute asthma, ${ }^{913} 14$ and indeed our follow up showed a high incidence of further IPPV episodes and of sudden death from asthma. There may be different mechanisms that predispose preschool and teenage asthmatics to respiratory failure. Young children have intrinsically narrower airways, may develop respiratory muscle fatigue more readily, and are less responsive to bronchodilators. Adolescents tend to comply poorly with treatment, may start to smoke, and may deny symptoms and therefore present later to hospital. The three children who presented to hospital after a respiratory arrest were aged 12, 14 , and 15 years.

Asthmatics who survive IPPV tend to continue to have daily symptoms and considerable life disturbance, and although many experience further life threatening episodes, few have either a clear plan of action or extra treatment available at home to cope with a severe attack.

In the four large published series (comprising 19 to 30 episodes) of ventilated asthmatic children, all American, the mortality rate ranged from $0 \%$ to $5 \cdot 3 \%$ of episodes. ${ }^{1-4}$ In our series mortality was considerably higher, eight of $\mathbf{4 8}$ episodes $(17 \%)$ being fatal. No consistent differences were apparent between the American centres and Liverpool in management during IPPV, but in the American series the threshold for instituting IPPV appeared lower, and hence the ventilated children less severely ill. In Seattle for example, $5 \cdot 3 \%$ of all acute asthma admissions received IPPV $(0.6 \%$ in Liverpool), mean $\mathrm{pH}$ before intubation was 7.22 (7.09 in Liverpool), and 5\% of IPPV episodes followed a respiratory arrest (10\% in Liverpool).

We are still ventilating two to three asthmatic children per year, and it seems likely that IPPV could be avoided in some of these by improved medical management. Among the children we are ventilating, mortality appears unacceptably high, and is most commonly related to hypoxicischaemic encephalopathy before IPPV. Much of this was occurring in hospital, and again should be preventable. The main inadequacies identified by our study were inconsistency in management (for example, failure to start steroids early), reluctance to use intravenous $\beta$ agonists, reluctance to measure blood gases, and failure to diagnose respiratory failure early. We have attempted to correct these deficiencies by introducing a written protocol for inpatient management of acute asthma by junior staff. Early clinical diagnosis of hypoxia and respiratory failure is essential but difficult, and to measure arterial blood gases on all asthmatic children admitted would be neither practicable nor desirable. Semiobjective clinical scoring systems have been advocated, ${ }^{12}$ but have not been proved to be of value. Pulse oximetry, now becoming more widely available, should allow earlier detection of hypoxia.

Ventilation is still required during some episodes of acute asthma despite improvements in the treatment available. Improved monitoring of children admitted with acute asthma and intensive treatment of early respiratory failure are neccessary to reduce the need for IPPV and avoid hypoxic brain damage. Survivors continue to suffer from severe chronic asthma and are at risk of sudden death from their disease. They require close follow up into adult life and must have a clear action plan for acute attacks.

1 Woods DW, Downes JJ, Lecks HI. The management of respiratory failure in childhood status asthmaticus. Experience with 30 episodes and the evolution of a technique. foumal of Allergy 1968;42:261-8.

2 Parry WH, Martorano F, Cotton EK. Management of lifethreatening asthma with intravenous isoproteronol infusions. Am F Dis Child 1976;130:39-42.

3 Simons FER, Pierson WE, Bierman CW. Respiratory failure in childhood status asthmaticus. Am $\mathcal{F}$ Dis Child 1977;131:1097-101.

4 Dworkin G, Kattan M. Mechanical ventilation for status asthmaticus in children. $f$ Pediatr 1989;114:545-9.

5 Simpson H, Mitchell I, Inglis JM, Grubb DJ. Severe ventilatory failure in asthma in children. Arch Dis Child tory failure in

6 Polgar G, Weng TR. The functional development of the respiratory system. Am Rev Respir Dis 1979;120:625-95.

7 Cockcroft DW, Killian DN, Mellon JJA, Hargreave FE. Bronchial reactivity to inhaled histamine: a method and clinical survey. Clin Allergy 1977;7:235-43.

8 Mitchell EA. International trends in hospital admission rates for asthma. Arch Dis Child 1985;60:376-8.

9 Office of Population Censuses and Surveys. Mortality statistics series. (DH2 Nos 1-12.) London: HMSO, 1977-1987.

10 Bohn D, Kalloghlian A, Jenkins J, Edmonds J, Barker G. Intravenous salbutamol in the treatment of status asthmaticus in children. Crit Care Med 1984;12:892-95.

11 Sury MR, Russell GN, Heaf DP. Hydrocortisone myopathy. Lancet 1988;ii:515.

12 Wood DW, Downes JJ, Lecks HI. A clinical scoring system for the diagnosis of respiratory failure. Am $\mathcal{J}$. Dis Child 1972;123:227.

13 Carswell F. Thirty deaths from asthma. Arch Dis Child 1985;60:25-8.

14 Speight ANP, Lee DA, Hey EN. Under diagnosis and under treatment of asthma in childhood. $\mathrm{Br}$ Med $\mathrm{f}$ 1983;286:1256-8.

\section{Commentary}

Mortality from asthma in the United Kingdom is unchanged or even rising, ${ }^{1}$ despite the advent of new drugs, more publicity, greater critical appraisal of treatment policies, earlier hospital admission, and the wider availability of mechanical ventilation (IPPV). The asthmatic process is reversible in a high proportion of patients and mechanical ventilation should, in theory, buy time for other measures to take effect. Nevertheless, most series describing the outcome of IPPV for severe acute asthma in adults 